\title{
Infected thyroglossal duct cyst
}

\author{
Puneet Bhargava $\cdot$ Marguerite Parisi
}

Received: 4 November 2009 /Revised: 17 December 2009/Accepted: 5 January 2010 /Published online: 5 February 2010

(C) Springer-Verlag 2010

A 5-year-old boy presented with a 4-day history of midline neck tenderness and swelling. Examination revealed a firm, palpable, mobile, erythematous midline neck mass that moved with tongue protrusion. Axial contrast-enhanced CT scan of the neck $\left(\mathrm{CTDI}_{\mathrm{Vol}}\right.$ 12.76 mGy, Fig. 1) with sagittal reconstruction (Fig. 2) revealed a thick-walled, rim-enhancing, cystic midline

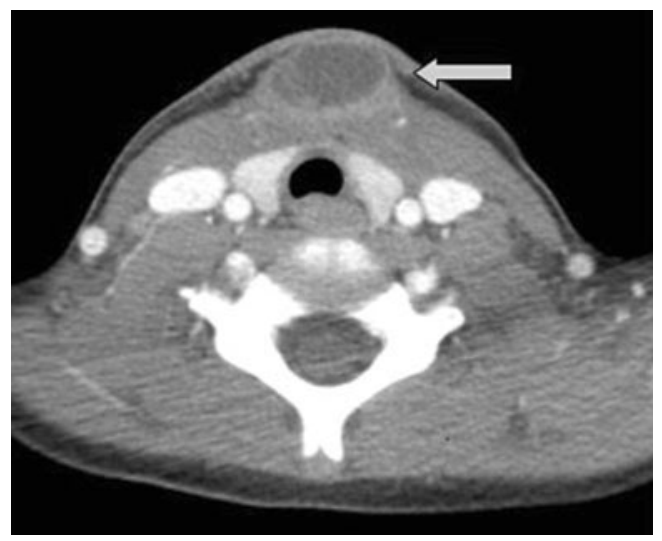

Fig. 1 Contrast-enhanced axial CT neck image

P. Bhargava $(\square)$

Department of Radiology, University of Washington \& VA Puget

Sound Health Care System,

Mailbox 358280, S-114/Radiology, 1660 S. Columbian Way,

Seattle, WA 98108, USA

e-mail: bhargp@u.washington.edu

\section{Parisi}

Department of Radiology,

University of Washington and Seattle Children's Hospital, 4800 Sand Point Way NE, MS R-5417,

Seattle, WA 98105, USA

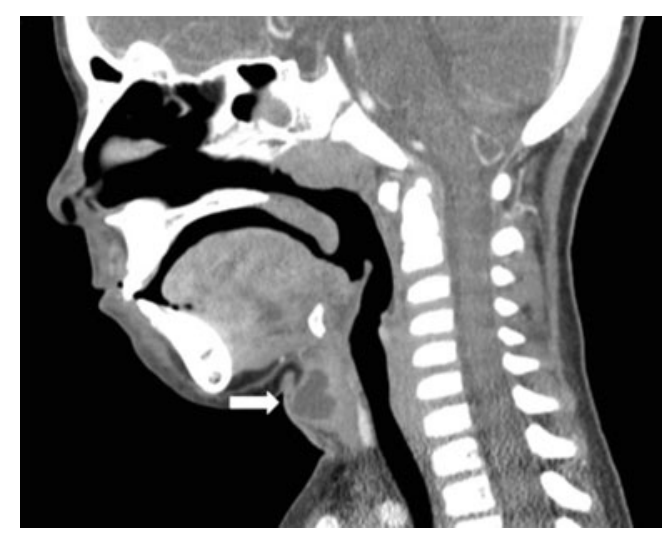

Fig. 2 Contrast-enhanced sagittal CT neck image

mass (arrow) inferior to the hyoid bone and anterior to the normal thyroid gland.

Thyroglossal duct cysts are the most common cause of midline neck masses. These can be found at any level from the base of the tongue to the isthmus of the thyroid gland. Most (65\%) are infrahyoid in location [1]. Initial treatment consists of antibiotics. Following control of the underlying infection, elective surgery (Sistrunk operation) is usually performed to remove the cyst to prevent recurrence [2].

\section{References}

1. Vazquez E, Enriquez G, Castellote A et al (1995) US, CT, and MR imaging of neck lesions in children. Radiographics 15:105-122

2. Kaselas C, Tsikopoulos G, Chortis C et al (2005) Thyroglossal duct cyst's inflammation. When do we operate? Pediatr Surg Int 21:991-993 